\title{
Modulation by aspartate of ischemia/reperfusion-induced oxidative stress in rat liver
}

\author{
Yeong-Chul Park, ${ }^{1}$ Se In Oh, ${ }^{1}$ Yong Hoon \\ Park $^{1}$ and Sang Chul Park ${ }^{1,2}$ \\ 1 Department of Biochemistry, College of Medicine, \\ Seoul National University, Seoul, Korea \\ 2 Corresponding author \\ Accepted 6 January 1997
}

Abbreviations: $\mathrm{XO}$, xanthine oxidase; $\mathrm{XDH}$, xanthine dehydrogenase; TBARS, thiobarbituric acid-reactive substance; TBA, thiobarbituric acid; AST, aspartate aminotransferase; $\mathrm{MDH}$, malate dehydrogenase oxidative damages.

Key words: ischemia/reperfusion injury, rat liver, oxidative stress, aspartate, xanthine oxidase

\section{Introduction}

Ischemia/reperfusion injury is associated with the production of oxygen-derived free radicals inducing lipid peroxidation, which cause alterations in biomembraneassociated functions of the cell or subcellular organelles. Ischemia/reperfusion-induced radical generation has been partially explained by the conversion of xanthine dehydrogenase (XDH) into xanthine oxidase (XO) (Parks et al., 1982; Roy and McCord, 1983). XDH can be converted to $\mathrm{XO}$ irreversibly by proteolysis or reversibly by sulfhydryl oxidation during the ischemia/ reperfusion process. And the ischemia causes the cellular increase of $\mathrm{NADH}$, which has been shown to inhibit the activity of $\mathrm{NAD}^{+}$-dependent $\mathrm{XDH}$ (Ballard, 1971; Kato et al., 1990). In consequence, the oxygendependent $X O$ pathway is activated to oxidize hypoxanthine and xanthine with a burst of superoxide. Moreover, the increased breakdown of ATP during ischemia aggravates accumulation of xanthines, requiring their metabolic conversion to uric acid by xanthine oxidase (Kamiike et al., 1982; Engerson et al., 1987)

It was recently reported that treatment of previously hypoxic hepatocytes with ethanol increased cellular toxicity (Khan and O'Brien, 1995). Ethanol further aggra-vated the ischemia-induced aberrant ratio of $\mathrm{NADH}$ to $\mathrm{NAD}^{+}$, since the bulk of the reducing power (NADH) is produced during ethanol oxidation. It is therefore reasonable to speculate that the involvement of both ischemia and ethanol in the alteration of the cellular redox state is one of the important factors in free radical-mediated liver injury. The control of cytosolic $\mathrm{NADH}$ in relation to the conversion of $\mathrm{XDH}$ to $\mathrm{XO}$ can thus contribute to the development of new therapeutic strategies against ischemia/reperfusion injury.

We have recently suggested that aspartate can protect against oxidative stress-induced tissue damage in ethanol-perfused rat livers (Park and Park, 1995; Park et al., 1996). Aspartate reduces the ethanol-induced conversion of $\mathrm{XDH}$ into $\mathrm{XO}$ by modulating the cytosolic $\mathrm{NADH} / \mathrm{NAD}$ ratio, since aspartate is a direct substrate for the malate-aspartate shuttle, which is the main pathway for transferring reducing equivalents originating from the cytosol to the mitochondria.

It is therefore assumed that aspartate supplementation would also contribute to restoring the cellular balance of 
NADH/NAD, disturbed during ischemia/reperfusion, through which oxidative tissue damage might be reduced. In the present investigation, aspartate was infused to rat liver during the ischemia/reoxygenation period, and the level of lipid peroxidation and activities of $\mathrm{XDH}$ and $\mathrm{XO}$ were monitored in order to evaluate the modulation of ischemia/reperfusion-induced liver damage.

\section{Materials and Methods}

\section{Experimental protocol}

Rats were divided into three main groups: control, ischemia, and reoxygenation, as shown in Figure 1. Each group was subdivided according to aspartate supplementation in perfusion into a (without) and $b$ (with aspartate). In the control group, after 15 min of washing, the livers were perfused with oxygenated buffer for 60 min. Hypoxia of the liver was produced by replacing oxygen-saturated buffer with nitrogen-saturated buffer. During the first $30 \mathrm{~min}$ of perfusion the ischemia state was maintained. Reoxygenation of the ischemia liver was achieved by replacing the perfusate with the oxygen-saturated buffer. Each group was also infused with $2 \mathrm{mM}$ aspartate from the starting point or after the ischemia state.

\section{Liver Perfusion}

Male Sprague-Dawley rats weighing $240 \pm 10 \mathrm{~g}$ were used for all experiments. An in situ perfusion technique employed was a modification of that previously described (Reinke et al., 1982; Deaciuc et al., 1992). The portal vein and the inferior vena cava were cannulated; the basic perfusate consisted of a standard Krebs-Ringer bicarbonate buffer containing $0.1 \%$ glucose at $\mathrm{pH} 7.4$. For one hour prior to and throughout the perfusion, the perfusate was gassed with a mixture of $95 \% \mathrm{O}_{2}$ and $5 \%$ $\mathrm{CO}_{2}$, and stirred at a hydrostatic pressure of $20 \mathrm{~cm}$ of water to ensure complete saturation with oxygen; its flow rate was $5 \mathrm{ml} / \mathrm{min}$.

\begin{tabular}{|c|c|}
\hline Control & $\begin{array}{l}\text { group 1-a ========== }(-) \text { aspartate } \\
\text { group 1-b ========== }(+) \text { aspartate }\end{array}$ \\
\hline Ischemia & 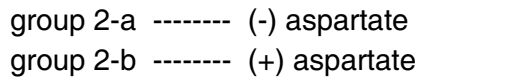 \\
\hline Reoxygenation & $\begin{array}{l}\text { group 3-a -------====== }(-) \text { aspartate } \\
\text { group 3-b ------====== }(+) \text { aspartate }\end{array}$ \\
\hline erfusion time & 30 \\
\hline
\end{tabular}

Figure 1. Diagram of experimental procedures. Single dotted lines indicate the ischemic state, while double dotted lines, reoxygenation state.

\section{Sample Preparation}

After perfusion, livers were excised and kept frozen at $70^{\circ} \mathrm{C}$. In order to analyze for lipid peroxidation, $10 \%$ $(w / v)$ liver homogenates were prepared in $0.15 \mathrm{M} \mathrm{NaCl}$. Meanwhile, $0.1 \mathrm{M}$ Tris- $\mathrm{HCl}$ buffer $(\mathrm{pH} 8.1)$ containing $0.1 \mathrm{mM}$ EDTA, $0.2 \mathrm{mM}$ phenylmethanosulfonyl fluoride, $1 \mathrm{mM}$ benzamidine hydrochloride, $1 \mathrm{mM}$ aprotinin and 1 $\mathrm{mM}$ dithiothreitol were used for $\mathrm{XDH}$ and $\mathrm{XO}$ assay.

\section{Analytical procedure and enzyme assay}

Lipid peroxidation was assessed by the measurement of thiobarbituric acid-reactive substance (TBARS) (Esterbaur et al., 1990). The homogenates were added to an equal volume of thiobarbituric acid (TBA) reagent (0.375\% TBA, $15 \%$ trichloroacetic acid, $0.25 \mathrm{M} \mathrm{HCl}$ ). After mixing, samples were heated for $15 \mathrm{~min}$ in a boiling water bath and centrifuged at $800 \mathrm{~g}$ for $10 \mathrm{~min}$ after cooling. The supernatant was monitored for its absorbance at $535 \mathrm{~nm}$, and its TBARS (malondialdehyde, MDA) content was determined by using an extinction coefficient of $156,000 \mathrm{M}^{-1} \mathrm{~cm}^{-1}$.

$\mathrm{XDH}$ and $\mathrm{XO}$ activities were measured using a slight modification of the methods described previously (Kato et al., 1990; Waud et al., 1976). The samples $(100 \mu \mathrm{l})$ was added to the reaction mixture containing $0.2 \mathrm{mM}$ xanthine, $0.1 \mathrm{M}$ Tris- $\mathrm{HCl}$ buffer $(\mathrm{pH} \mathrm{8.1)}$ with $0.1 \mathrm{mM}$ EDTA in a final volume of $1 \mathrm{ml}$. Activity was monitored by reading optical densities at 295 and $340 \mathrm{~nm}$ in the absence or presence of $0.5 \mathrm{mM} \mathrm{NAD}^{+}$at $30^{\circ} \mathrm{C}$. One unit (U) of the activity of either enzyme is defined as the amount of enzyme required to produce $1 \mu \mathrm{mol}$ of $\mathrm{NADH}$ or $1 \mu \mathrm{mol}$ of uric acid per min, respectively. Specific activity was calculated as milliunit $(\mathrm{mU})$ per $\mathrm{mg}$ protein. Protein was determined by the method of Lowry et al. (1951).

\section{Results}

In the present study, rats were divided on the basis of perfusion time and pattern into three groups as follows: control, ischemia and reoxygenation. Each group was also divided into two subgroups, depending on the addition of aspartate (Figure 1). The level of lipid peroxidation in each group is shown in Table 1 . In control groups, the amounts of TBARS were $0.174 \pm 0.009$ and $0.166 \pm 0.013 \mathrm{nmol} / \mathrm{mg}$ protein, respectively, showing no significant difference in the absence or presence of aspartate. Their amounts of TBARS were slightly less than those in the ischemia groups but not significant $(P$ $>0.05$ ). In the ischemia groups, the addition of aspartate did not cause any significant changes in the level of lipid peroxidation $(P>0.05)$. However, the amount of TBARS in the reoxygenation group in the absence of aspartate was $0.214 \pm 0.003 \mathrm{nmol} / \mathrm{mg}$ protein, resulting in $25 \%$ increase compared to the control and ischemia 
groups. This increase was not observed in aspartatetreated reoxygenation group. The amount of TBARS in this group was $0.180 \pm 0.001 \mathrm{nmol} / \mathrm{mg}$ protein. These results indicate that aspartate may play a role in preventing ischemia/reperfusion injury by reducing the level of TBARS.

To identify their role in the change of TBARS levels, specific activities of the enzymes, $\mathrm{XDH}$ and $\mathrm{XO}$, were measured and the degree of conversion of $\mathrm{XDH}$ to $\mathrm{XO}$ was expressed as a ratio, as shown in Table 2. In control groups, the ratio of $\mathrm{XDH}$ to $\mathrm{XO}$ was about 7.17 to 7.7 without any significant difference. A similar tendency was observed in the ischemia groups, where the ratio was 6.7 to 6.9 in the absence or presence of aspartate. Decrease in the ratio of $\mathrm{XDH}$ to $\mathrm{XO}$ was observed in the reoxygenation group (30 min of oxygenated reperfusion following $30 \mathrm{~min}$ ischemia) compared to the control and ischemia groups. In addition, the ratios in the reoxygenation group were significantly different in response to aspartate infusion, being 4.36 for non-aspartate treatment and 5.22 for aspartate treatment, respectively $(P<0.05)$. This indicates that aspartate infusion can partially correct the ischemia/reperfusion-induced decrease of the $\mathrm{XDH} / \mathrm{XO}$ ratio.

\section{Discussion}

The effect of aspartate infusion on ischemia/reperfusion induced lipid peroxidation in the liver is shown in Table 1. The levels of TBARS, indicative of lipid peroxidation, was not much different between ischemia groups and control groups. The aspartate treatment to both groups did not cause any changes in the level of TBARS. However, it was found that TBARS level in the reoxygenation group was about $25 \%$ higher than those in the

Table 1. Levels of lipid peroxides in homogenate prepared from perfused rat liver. All the values are means \pm SD for three to four rats per group.

\begin{tabular}{cc}
\hline & TBARS $(\mathrm{nmol} / \mathrm{mg}$ protein) \\
\hline Control groups & $0.174 \pm 0.009$ \\
Group 1 & $0.166 \pm 0.013$ \\
Group 2 & \\
Ischemia groups & $0.148 \pm 0.010^{\mathrm{a}}$ \\
Group 3 & $0.159 \pm 0.006^{\mathrm{a}}$ \\
Group 4 & \\
Reoxygenation groups & $0.214 \pm 0.003^{\mathrm{b}}$ \\
Group 5 & $0.180 \pm 0.001^{\mathrm{b}, \mathrm{c}}$ \\
Group 6 &
\end{tabular}

\footnotetext{
a $P>0.05$ versus control groups.

${ }^{\mathrm{b}} P<0.05$ versus control groups.

${ }^{c} P<0.05$ versus group 5 .
}

control or ischemia groups. The major mechanism for ischemia/reperfusion injury was suggested to be the activation of $X O$. It is thus reasonable to consider modulation of conversion of $\mathrm{XDH}$ to $\mathrm{XO}$ to reduce the elevated level of TBARS.

In the present study, measured activity of $\mathrm{XDH}$ was consistent with that previously reported, showing approx. $90 \%$ activity of total XDH plus XO (Marubayashi et al., 1991). At the final time point, after $1 \mathrm{~h}$ ischemia/reoxygenation, approximately $20 \%$ of total enzyme is present in XO form (Table 2). These results thus indicate that the increased activity of $\mathrm{XO}$ was induced by the subsequent reoxygenation of the previously ischemic state. The increased activity of $\mathrm{XO}$ may be due to conversion of $\mathrm{XDH}$ into $\mathrm{XO}$, as suggested by no significant changes of the total activity of $\mathrm{XDH}$ plus $\mathrm{XO}$ in those groups.

It has been generally accepted that energy-rich adenine nucleotides are rapidly catabolized to hypoxanthine as oxygen deprivation occurs during ischemia (Malis \& Bonventre, 1986). Subsequent metabolism of purines by $\mathrm{XO}$ causes oxidative tissue damages. On the basis of this fact, the inhibition of XO and the salvage of substrates for nucleotides have been suggested as a mechanism to protect against ischemia/reperfusion injury (Manning et al., 1984; Stein et al., 1990). On the other hand, an increase in ischemia-induced $\mathrm{NADH}$ inhibits $\mathrm{NAD}^{+}$-dependent $\mathrm{XDH}$ activity. As mentioned above, increased NADH is associated with the increased breakdown of nucleotide and a shift from the $\mathrm{XDH}$ to the XO pathway in ischemia-reperfusion injury (Ballard, 1971; Engerson et al., 1987; Kato et al., 1990). NADH after ethanol treatment has been shown to inhibit $\mathrm{XDH}$ activity in vitro as well as in vivo; a similar observation in an ethanol study has shown enhanced degradation of purine, providing substrates for $\mathrm{XO}$. It has recently been

Table 2. Comparison of activities of $X D H$ and $X O$ in perfused rat liver tissues. Units of enzymatic activities are $\mathrm{mU} / \mathrm{mg}$ protein. All the values are means $\pm \mathrm{SD}$ for three to four rats per group.

\begin{tabular}{|c|c|c|c|}
\hline & $\mathrm{XDH}$ & $\mathrm{XO}$ & $\mathrm{XDH} / \mathrm{XO}$ \\
\hline \multicolumn{4}{|l|}{ Control groups } \\
\hline Group 1 & $12.45 \pm 0.15$ & $1.74 \pm 0.11$ & $7.17 \pm 0.36$ \\
\hline Group 2 & $16.25 \pm 2.15$ & $2.18 \pm 0.55$ & $7.69 \pm 0.96$ \\
\hline \multicolumn{4}{|c|}{ Ischemia groups } \\
\hline Group 3 & $14.25 \pm 0.05$ & $2.08 \pm 0.04$ & $6.86 \pm 0.04^{a}$ \\
\hline Group 4 & $15.20 \pm 0.40$ & $2.30 \pm 0.36$ & $6.74 \pm 1.24^{a}$ \\
\hline \multicolumn{4}{|c|}{ Reoxygenation groups } \\
\hline Group 5 & $12.30 \pm 0.40$ & $2.82 \pm 0.16$ & $4.36 \pm 0.375$ \\
\hline Group 6 & $12.05 \pm 0.95$ & $2.37 \pm 0.33$ & $5.22 \pm 0.20^{b, c}$ \\
\hline
\end{tabular}

a $P>0.05$ versus control groups.

${ }^{\mathrm{b}} P<0.05$ versus control groups.

${ }^{c} P<0.05$ versus group 5 . 
reported that the treatment of previously ischemia hepatocytes with ethanol increased cellular toxicity (Khan et al., 1995); this was explained by the fact that ethanol further increased the cellular aberrant ratio of $\mathrm{NADH}$ to $\mathrm{NAD}^{+}$induced by ischemia. In the present study, modulation in the altered redox state was assumed to be one of the mechanisms protecting against ischemia/reperfusion injury.

As shown in our previous papers (Park \& Park, 1995; Park et al., 1996), aspartate was effective in modulating the increased ratio of NADH to NAD ${ }^{+}$in ethanol-perfused rat liver by activating the malate-aspartate shuttle. That aspartate modulated the altered redox state in ethanolperfused liver was evidenced by the change in the lactate/pyruvate ratio in vascular effluents, a change which accurately reflects the cellular-free NAD ${ }^{+} / \mathrm{NADH}$ ratio. As a result of the corrected ratio of $\mathrm{NADH} / \mathrm{NAD}^{+}$ resulting from aspartate treatment, the increased $\mathrm{XO}$ activity resulting from ethanol infusion was significantly reduced with lower level of oxidative stress than control group. It is conceivable that aspartate may correct the increased $\mathrm{NADH} / \mathrm{NAD}^{+}$ratio by facilitating $\mathrm{NAD}^{+}$regeneration from $\mathrm{NADH}$ through $\mathrm{AST}$ - and $\mathrm{MDH}$-coupled reactions and by augmenting the malate-aspartate shuttle between the cytosol and mitochondria (Park, 1993). By the same reason, it would be possible to extend the idea that $\mathrm{NAD}^{+} / \mathrm{NADH}$ imbalance caused by any other reason might be corrected by aspartate supplementation. One of the typical disorders associated with the nucleotide coenzyme imbalance is the ischemia/ reperfusion injury, where the resulting oxidative tissue damage is well known.

Thus, in the present study, the ischemia/reperfusion injury in the liver tissue was studied to elucidate whether aspartate infusion would ameliorate the oxidative injury. As expected, the addition of aspartate to the liver perfusion system during the whole period of ischemia/ reoxygenation resulted in a reduced level of TBARS, and simultaneously decreasd the ratio of $\mathrm{XDH}$ to $\mathrm{XO}$ compared to that without aspartate $(P<0.05)$. The significant prevention by aspartate of lipid peroxidation in this ischemia/reperfusion liver tissue could be directly related with the inhibition of enzymic conversion of $\mathrm{XDH}$ to $\mathrm{XO}$ due to aspartate-induced cellular redox changes. Furthermore, the general possibility of modulating cellular ratio of $\mathrm{NADH}$ to $\mathrm{NAD}^{+}$by simple application of an amino acid suggests the wider application to varying ischemia/ reperfusion injuries.

In conclusion, our results indicate that aspartate would be effective in reducing the level of oxidative stress induced by ischemia/reperfusion. The effective role of aspartate in oxidative stress was shown by the reduced level of TBARS and the normalization of XDH to XO ratio. This result may thus contribute to the development of a possible therapy in the pathology generated by ischemia and reperfusion such as in the cases of organ transplantation, myocardiac infarction, muscle degeneration and various thrombo-embolic disorders, etc.

\section{Acknowledgement}

This work was partially supported by the grants from the Ministry of Education for Basic Medical Research Promotion Fund and from the Korea Research Foundation for Health Science.

\section{References}

Ballard, F. J. (1971) Regulation of gluconeogenesis during exposure of young rats to hypoxic conditions. Biochem. J. 121: 169-178

Deaciuc, I. V., D'Souza, N. B., Lang, C. H. and Spizer, J. S. (1992) Effects of acute alcohol intoxication on gluconeogenesis and its hormonal responsiveness in isolated, perfused rat liver. Biochem. Pharmacol. 44: 1617-1624

Engerson, T. D., McKelvey, T. G., Rhyne, D. B., Boggio, E. B., Snyder, S. J. and Jones, H. P. (1987) Conversion of xanthine dehydrogenase to oxidase in ischemic rat tissues. J. Clin. Invest. 79: 424-431

Esterbauer, H. and Cheeseman, K. H. (1990) Determination of aldehydic li[pid peroxidation products: malonaldehyde and 4-hydroxynonenal. Methods Enzymol. 186: 407-423

Faller, J. and Fox, I. H. (1982) Ethanol-induced hyperuricemia. Evidence for increased urate production by activation of adenine dinucleotide turnover. N. Engl. J. Med. 307: 1598-1602

Kato, S., Kawase, T., Alderman, J., Inatomi, N. and Lieber, C. S. (1990) Role of xanthine oxidase in ethanol-induced lipid peroxidation in rats. Gasteroenterology 98: 203-210

Khan, S. and O'Brien, P. J. (1995) Modulating hypoxia-induced hepatocyte injury by affecting intracellular redox state. Biochim Biophys. Acta 1269: 153-161

Kamiike W., Watanabe F., Hashimoto T., Tagawa K., Ikeda Y., Nakao K. and Kawashima Y. (1982) Changes in cellular levels of ATP and its catabolites in ischemic rat liver J. Biochem. 91: 1349-1356

Lowry, O. H., Rosenbrough, A. L., Farr, A. L. and Randall, R. J. (1951) Protein measurement with Folin phenol reagent. J. Biol. Chem. 193: 265-275

Malis, C. D. and Bonventre, J. V. (1986) Mechanism of calcium potentiation of oxygen free radical injury to renal mitochondria. A model for post-ischemic and toxic mitochondrial damage. J. Biol. Chem. 261(30): 14201-8

Manning, A. S., Coltart, D. J. and Hearse, D. J. (1984) Ischemia and reperfusioninduced arrythmias in the rat. Effects of xanthine oxidase inhibition with allopurinol. Circ. Res. 55: 545-548

Marubayashi, S., Dohi, K., Yamada K. and Kawasaki, T. (1991) Role of conversion of xanthine dehydrogenase to oxidase in ischemic rat liver cell injury. Surgery 110: 537543

Park, S. C. (1993) Ethanol oxidation is accelerated by augmentation of malate-aspartate shuttle with aspartate. Korean J. Biochem. 25: 137-143

Park, Y. C. and Park, S. C. (1995) Reduction of oxidative stress by aspartate in the ethanol-perfused rat liver tissues. Korean J. Biochem. 27: 165-169

Park Y. C. Oh, S. I., Lee, S. L. and Park, S. C. (1996) Effects of amino acids on ethanol metabolism and oxidative stress in the ethanol-perfused rat liver. Korean Env. Mutagen Carcinogen 16: 13-18

Parks, D. A., Bulkley, G. B., Granger, D. N., and McCord, J. M. (1982) Ischemic injury in the cat small intestine: role of superoxide radicals. Gastroenterology 82: 9-15 
Reinke, L. A., Belinsky, S. A., Kauffman, F. C., Evans, R. K. and Thruman, R. G. (1982) Regulation of NADPH- and NADH-dependent mixed-function oxidation in perfused livers. Biochem. Pharmacol. 31: 1621-1628

Roy, R. S. and McCord, J. M. (1983) Superoxide and ischemia: conversion of xanthine dehydrogenase to xanthine oxidase. In Proceeding of the Third International Conference on superoxide and superoxide dismutase (Greenwals, R and Cohen, G, eds.), pp. 145-153, Elsevier/North Holland Biomedical Press, New York

Stein, H. J., Hinder R. A. and Ooshuizen, M. M. (1990) Gastric mucosal injury caused by hemorrhagic shock and reperfusion: protective role of the antioxidant glutathione. Surgery 108: 467-74

Waud, W. R. and Rajagopalan, K. V. (1976) Purification and properties of the NAD- dependent (Type $\mathrm{D}$ ) and $\mathrm{O}_{2}$-dependent (type $\mathrm{O}$ ) forms of rat liver xanthine dehydrogenase. Arch. Biochem. Biophys. 172: 354-364 